\title{
UC shores up research for CALFED: How do you slice the water pie?
}

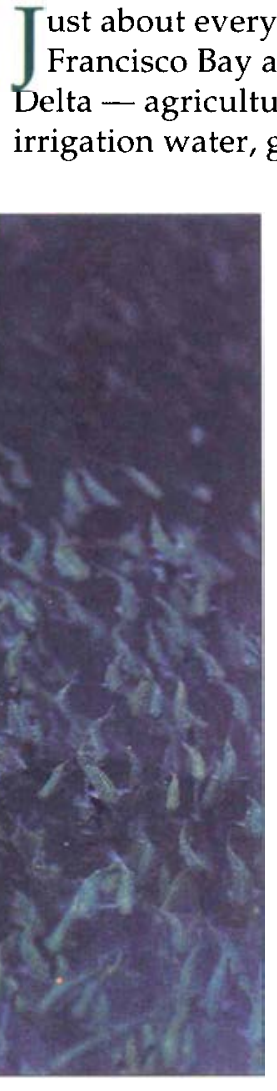
ust about everyone wants water from the San
Francisco Bay and Sacramento-San Joaquin
Delta - agriculture wants a reliable supply of higher quality drinking water and environmentalists want more water to stay where it is. To help put an end to 20 years of wrangling over who gets how much water, President Bill Clinton and former governor Pete Wilson formed the CALFED Bay-Delta Program in 1995. A partnership of seven state and federal agencies, CALFED's goal is to restore the Bay-Delta's ecological health while improving the reliability and quality of the water supply for agricultural and urban users.

The Bay-Delta is the largest estuary on the west coast of the Americas and is home to 750 species of plants and animals. The Bay-Delta also supplies drinking water to two-thirds of Californians

New Bay-Delta guidelines protect at-risk species, including Delta smelt and chinook salmon. Pictured above are chinook and steelhead fingerlings bred from new wild fish to enhance natural populations. and irrigation water for more than seven million acres of farmland. With a watershed that drains more than one-third of the state, the Delta's inflow averages 24 million acre feet per year but has dipped as low as a quarter of that during drought years. There are more than 7,000 water projects that together divert $20 \%$ to $70 \%$ of the Delta's natural flow.

CALFED is divided into three phases. The first phase, defining the fundamental problems and goals, was completed in 1996. The second phase, a comprehensive "big picture" environmental review, is expected to be completed by the end of this year. The third phase, sitespecific detailed environmental reviews prior to the implementation of each action, is expected to take several decades.
UC researchers are contributing to the CALFED process in a variety of ways. When Gray Davis was elected governor, he commissioned a transition team to evaluate CALFED. Called the Agriculture and Water Transition Task Force, this approximately 30 -member team included UC Berkeley agricultural economist Jerry Siebert and UC Davis Dean of Agricultural and Environmental Studies Barbara Schneeman. "Our basic recommendation was to endorse the CALFED process," says Siebert. "Instead of warring, maybe we can find a way to meet all our needs. It's got to be done."

To write its strategic plan for ecosystem restoration, CALFED assembled a six-member team that included UC Davis aquatic ecologist Peter Moyle, UC Berkeley river processes expert Mathias Kondolf and UC Berkeley environmental policy expert Robert Twiss. The team defined goals and set priorities for rehabilitating the Bay-Delta. CALFED adopted the team's guidelines in December.

The guidelines set the most important goal as protecting the Bay-Delta's at-risk species, which include the Delta smelt, chinook salmon and about 70 other species that depend on the Delta and Suisun Bay. Keeping these species off the endangered species list is key to retaining CALFED's flexibility, says Moyle. And the best way to protect Bay-Delta species is to restore the system's natural processes including river meanders and flooding, says Moyle.

The team also recommended that CALFED monitor its restoration projects. "There are a lot of things we don't know about the Bay-Delta system and about ecosystem restoration," says Moyle. "Monitoring will tell us what works and what doesn't." While this may seem obvious, restoration projects are often set up and then left alone, says Moyle.

To help CALFED evaluate the effectiveness of its actions, UC Davis geologist Jeffrey Mount is leading an effort to develop a long-term monitoring program for the Cosumnes River Basin. This would be the first comprehensive 
monitoring program for a watershed and Mount would like to tailor it to meet CALFED's needs. "The Cosumnes basin is relatively small and has all the elements CALFED is interested in from floodplains to groundwater," says Mount.

At the request of CALFED director Lester Snow, Mount has also helped streamline the working relationship between CALFED and the University of California. The resulting interagency agreement stipulates the details of the many ways UC can contribute to CALFED, from doing research to assembling databases to running conferences. "This will help UC do a better job meeting the research and education needs of CALFED," says Mount. An immediate benefit of the streamlined relationship is that while it typically takes 3 months for grants to get started, it only takes a couple of weeks under the new agreement.

Other UC researchers are evaluating the economics of CALFED. UC Berkeley agricultural economist David Sunding is studying the economic value to the state of increasing the reliability of urban and agricultural water supplies. "CALFED could cost up to $\$ 12$ billion," says Sunding. "It's important to spend the money wisely because taxpayers are not at the table." Before building more dams and other water storage facilities, Sunding recommends increasing the efficiency of agricultural water use. One way of encouraging efficiency would be to promote water trading among farmers, which is already becoming more common in California.

To help determine how much water could be conserved by agriculture, CALFED formed a five-member team which included plant wateruse expert Ted Hsiao, hydrologist Mark Grismer and emeritus agricultural economist Charles Moore, all of UC Davis. Called the Independent Review Panel on Agricultural Water Conservation Potential, the team evaluated the methods CALFED used for assessing the potential for conserving agricultural water. "They've made a good start," says Hsiao. "But the details will have to be worked out region by region." CALFED has also formed similar independent review panels to assess how much water could be conserved by other users.

Another independent team of UC researchers was formed at the request of the state Resources Agency, which is a CALFED member.

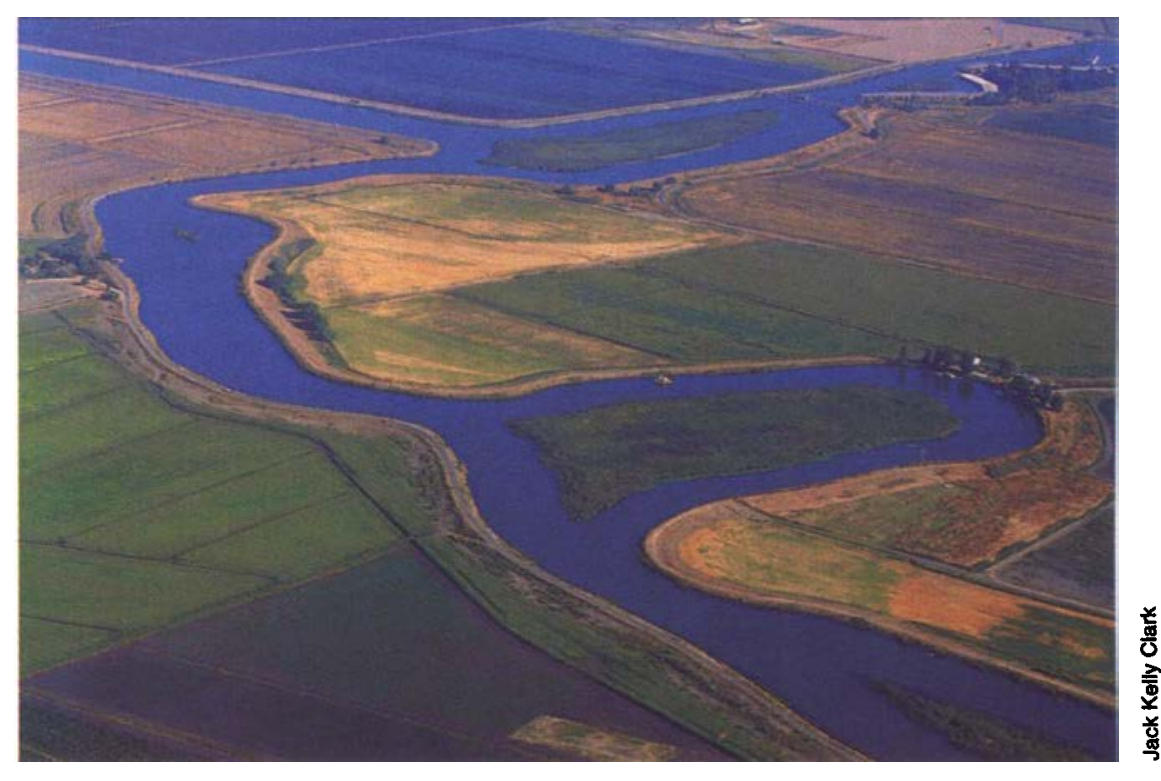

UC Davis agricultural economist Richard Howitt and UC Davis systems engineer Jay Lund are collaborating on a study that includes determining the economic value of proposed new water structures such as storage facilities and a canal to divert water to Southern California and the Central Valley.

Howitt and Lund are developing a model of the state's main water system, which extends from Shasta-Trinity to Southern California. The model assumes that the amount of water allocated to the environment is fixed; and it then maximizes the economic value of water allocated to agriculture and urban areas. The model accounts for factors including water allocations for urban areas; efficiency of use for each agricultural region; river and canal flows; and reservoir and groundwater storage. "This is the first detailed model of the entire state," says Lund. "We'd like to use it to encourage statewide water planning."

Once CALFED figures out how to restore the Bay-Delta ecosystem while providing reliable amounts of water to agriculture and urban areas, the big question will be how to pay for it all. Identifying who would be willing to pay for new water facilities and determining how much they would be willing to pay is another major objective of Howitt and Lund's study. "We can't name a figure yet but I'm surprised to see how much farmers would be willing to pay during extreme situations, such as high value crops during a drought year," says Lund.
CALFED aims to restore the Bay-Delta's ecological health.

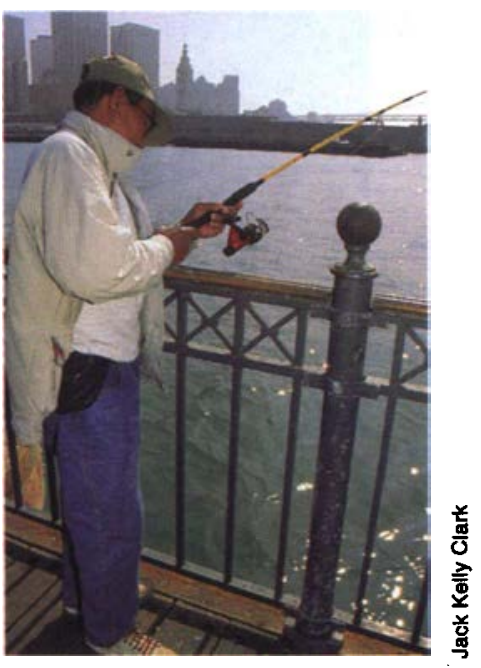

Fishers have been warned that PCB's, mercury and other pollutants may contaminate fish in San Francisco Bay. One of CALFED's goals is to reduce the effects of toxic substances on the ecosystem. 